Note

\section{Aminomethanesulfonic Acid as an Inhibitor of Photorespiration}

\author{
Chol Cho, Jin-Myeon KIM, \\ Ryuichi IsHII, ${ }^{*}$ Suong-Be HyeON \\ and Akinori SuzUKI \\ Department of Agricultural Chemistry, \\ The University of Tokyo, \\ Bunkyo-ku, Tokyo \\ 113, Japan \\ *Department of Agrobiology, The University \\ of Tokyo, Bunkyo-ku, Tokyo \\ 113, Japan
}

Received October 7, 1985

In the search for a potent inhibitor of photorespiration, we have been screening various chemicals by measuring the so-called oxygen compensation point in isolated spinach cells with an oxygen electrode, and have found that aminoacetonitrile (AAN) and aminomethanesulfonic acid (AMS) are effective inhibitors. ${ }^{1)}$ The subsequent experiment characterized AAN as a specific and competitive inhibitor of photorespiration at the site of mitochondrial glycine oxidation in the glycolate pathway. ${ }^{2}$ Since then, AAN has been used for a study of the photorespiratory carbon metabolism in higher plants. ${ }^{3,4)}$ AMS, however, has not yet been characterized as a photorespiration inhibitor with respect to its specificity and inhibition site.

This study aims, firstly, at the characterization of AMS as an inhibitor of photorespiration; and, secondly, the photosynthesis under photorespiratory conditions is examined to check whether it is influenced by a photorespiration inhibitor.
Rice plants (Oryza sativa L. cv. Nipponbare) were grown in soil for about 2 months, and pea (Pisum sativum L.) and wheat (Triticum aestivum L.) were grown in vermiculite for 9 to 11 days in a natural-light phytotron at $25 / 20^{\circ} \mathrm{C}$ (day/night).

Four excised rice leaves were set in a leaf chamber with their bases submerged in distilled water. Photorespiratory and respiratory $\mathrm{CO}_{2}$ exchanges were measured as $\mathrm{CO}_{2}$ evolution into $\mathrm{CO}_{2}$-free air in the light and dark, using the system previously reported. ${ }^{5)}$ Photosynthetic $\mathrm{CO}_{2}$ uptakes under non-photorespiratory and photorespiratory conditions were measured in air containing $2 \% \mathrm{O}_{2}$, and in normal atmospheric air. AMS, adjusted to $\mathrm{pH} 7.0$ with $\mathrm{KOH}$, was applied with a syringe to the distilled water immediately after the rate of $\mathrm{CO}_{2}$ exchange reached the steady state.

The photosynthetic $\mathrm{O}_{2}$ evolution by wheat protoplasts in the presence of $10 \mathrm{~mm} \mathrm{NaHCO} 3$ and the respiratory $\mathrm{O}_{2}$ uptake by pea mitochondria were measured polarographically with an oxygen electrode (Hansatech, King's Lynn, UK) according to Edwards et $a l^{6)}$ and Usuda et al., ${ }^{2)}$ respectively. The photosynthetic rate thus measured in the presence of $10 \mathrm{~mm} \mathrm{NaHCO}$ represents the rate under nonphotorespiratory conditions, because the $\mathrm{CO}_{2}$ concentration was sufficient to suppress the RuBP oxygenase reaction.

The inhibition site of AMS was identified by investigating the effect of AMS on several enzymes in the glycolate pathway under suitable conditions. The activity of glycolate oxidase was assayed at $30^{\circ} \mathrm{C}$ with an oxygen electrode according to Jewess et al. . $^{7}$ The activities of hydroxypyruvate reductase and glutamate:glyoxylate aminotransferase, and of serine: glyoxylate aminotransferase were assayed spectrophotometrically at $25^{\circ} \mathrm{C}$ according to Brock et al. ${ }^{8)}$ and Rehfeld and Tolbert, ${ }^{9)}$ respectively. Mitochondrial glycine oxidation was measured at $25^{\circ} \mathrm{C}$ with an oxygen electrode according to Usuda et $a l^{2)}$

Glycolate oxidase and hydroxypyruvate reductase were purchased from Sigma, the other enzymes being prepared according to Jenkins et al. ${ }^{10)}$

Table I. Inhibitory Effect of AMS on Photorespiration, Respiration and Photosynthesis

\begin{tabular}{|c|c|c|c|c|c|}
\hline \multicolumn{6}{|c|}{ Inhibition $(\%)$} \\
\hline \multirow{2}{*}{ AMS } & \multirow{2}{*}{$\begin{array}{c}\text { Photorespiration } \\
{\text { (Leaf })^{a}}^{a}\end{array}$} & \multicolumn{2}{|c|}{ Respiration } & \multicolumn{2}{|c|}{ Photosynthesis* } \\
\hline & & $(\text { Leaf })^{b}$ & $(\text { Mito. })^{c}$ & $(\text { Leaf })^{d}$ & $(\text { Proto. })^{e}$ \\
\hline $5 \mathrm{mM}$ & 15 & 0 & 0 & 0 & 0 \\
\hline $10 \mathrm{~mm}$ & 28 & 0 & 0 & 7 & 5 \\
\hline
\end{tabular}

Light intensity during the measurement was $800 \mu \mathrm{E} \mathrm{m}^{-2} \mathrm{~s}^{-1}$ in $a, d$ and $e$. Temperature was $25^{\circ} \mathrm{C}$ throughout the measurement. The control rates for $a, b$ and $d$ were $4.5 \sim 5.0,2.5 \sim 3.5$ and $31.3 \sim 34.8 \mathrm{mg} \mathrm{CO}_{2} / \mathrm{dm}^{2} / \mathrm{hr}$, respectively; $c$ and $e$ were $105 \sim 120 \mathrm{nmol} \mathrm{O}_{2} / \mathrm{mg}$ protein $/ \mathrm{min}$ and $115 \sim 125 \mu \mathrm{mol} \mathrm{O} \mathrm{O}_{2} / \mathrm{mg} \mathrm{chr} / \mathrm{hr}$, respectively.

* Photosynthesis under the non-photorespiratory condition. 


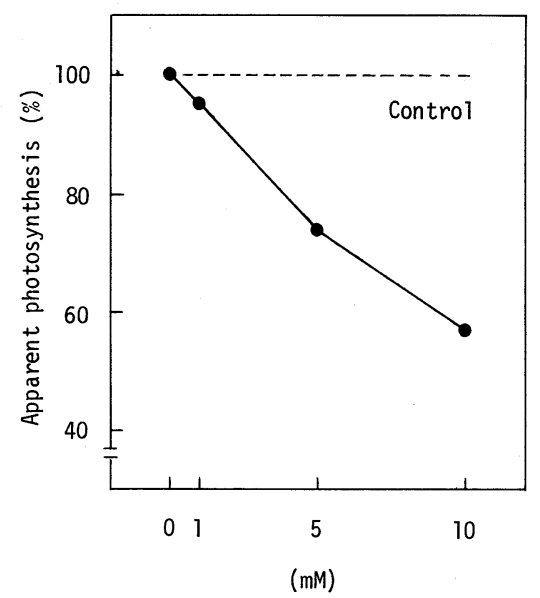

Fig. 1. Concentration Effect of AMS on Apparent Photosynthesis in Excised Rice Leaves.

The rate of apparent photosynthesis in the absence of AMS was $25 \sim 27 \mathrm{mg} \mathrm{CO}_{2} / \mathrm{dm}^{2} / \mathrm{hr}$. The light intensity and temperature were the same as these in Table I.

Table I shows the effect of AMS on photorespiration, respiration and photosynthesis under the nonphotorespiratory condition. AMS inhibited photorespiration as strongly as aminoacetonitrile, ${ }^{11)}$ but did not affect either respiration or photosynthesis under this condition. These results could indicate that AMS has a high specificity for the inhibition of photorespiration.

An assay of the inhibitory effect of AMS on the enzymes in the glycolate pathway and of the mitochondrial glycine oxidation revealed that AMS inhibited the photorespiration by affecting glycolate oxidase and hydroxypyruvate reductase. AMS showed a non-specific inhibition $\left(K i=1.1 \times 10^{-5} \mathrm{M}\right)$ in glycolate oxidase and a noncompetitive inhibiton $\left(K i=2.7 \times 10^{-3} \mathrm{M}\right)$ in hydroxypyruvate reductase.

We further investigated the effect of AMS on photosynthesis under the photorespiratory condition; this is, the apparent photosynthesis under normal air conditions. As shown in Fig. 1, AMS clearly inhibited the apparent photosynthesis, and the inhibition extent increased with the increase of AMS that was applied. The inhibition of photosynthesis under the photorespiratory condition was not due to direct inhibition of the photosynthetic mech- anism, but to the inhibition of photorespiration, because AMS did not affect at all photosynthesis under the non-photorespiratory condition (Table I). Mulligan et $a l .{ }^{12)}$ have shown, with spinach chloroplasts, that glycolate inhibited $\mathrm{CO}_{2}$ fixation. Therefore, it is postulated that the inhibition of photosynthesis under the photorespiratory condition by AMS is due to the accumulation of glycolate caused by the inhibition of glycolate oxidase.

It has been reported by us ${ }^{5}$ and some workers ${ }^{2,13)}$ that AAN, a specific inhibitor of mitochondrial glycine oxidation, decreased photosynthetic $\mathrm{CO}_{2}$ fixation under the photorespiratory condition. AMS also decreased photosynthesis under photorespiratory condition, although AMS had an inhibition site different from AAN in the photorespiratory glycolate pathway. From these results, it seems difficult to accelerate the net photosynthetic $\mathrm{CO}_{2}$ uptake by means of photorespiration inhibitors.

\section{REFERENCES}

1) H. Ishibashi, S. J. Yun, S. B. Hyeon, A. Suzuki and S. Tamura, Agric. Biol. Chem., 42, 1807 (1978).

2) H. Usuda, G. P. Arron and G. E. Edwards, J. Exp. Bot., 31, 1477 (1980).

3) D. J. Oliver, Plant Physiol., 68, 1032 (1981).

4) C. J. Chastain and W. L. Ogren, Plant Physiol., 77, 851 (1985).

5) C. Cho, J. M. Kim, R. Ishii, S. B. Hyeon and A. Suzuki, Agric. Biol. Chem., 49, 2847 (1985).

6) G. E. Edwards, S. P. Robinson, N. J. C. Tyler and D. A. Walker, Plant Physiol., 62, 313 (1978).

7) P. J. Jewess, M. W. Kerr and D. P. Whitaker, FEBS Lett., 53, 292 (1975).

8) B. L. W. Brock, D. A. Wilkinson and J. King, Can. J. Biochem., 48, 486 (1970).

9) D. W. Rehfeld and N. E. Tolbert, J. Biol. Chem., 247, 4803 (1972).

10) C. L. D. Jenkins, L. J. Rogers and W. Kerr, Phytochemistry, 22, 347 (1983).

11) C. Cho, Y. Sugimoto, J. M. Kim, H. Usuda, R. Ishii, S. B. Hyeon and A. Suzuki, Agric. Biol. Chem., 47, 2685 (1983).

12) R. M. Mulligan, B. Wilson and N. E. Tolbert, Plant Physiol., 72, 415 (1983).

13) E. Creach and C. R. Stewart, Plant Physiol., 70, 1444. (1982). 